\title{
Outcomes of Management of Anal and Perianal Suppuration at Niamey National Hospital, Niger
}

\author{
Rachid Sani ${ }^{1}$, Harissou Adamou ${ }^{2, ~ *}$, Lassey Didier James ${ }^{1}$, Ibrahim Amadou Magagi ${ }^{2}$, \\ Younssa Hama ${ }^{1}$, Adama Saidou ${ }^{1}$, Kadi Idé ${ }^{1}$, Illa Hamidine ${ }^{2}$, Hadjara Dady ${ }^{3}$, \\ Maman Sani Chaibou ${ }^{3}$ \\ ${ }^{1}$ Department of General and Digestive Surgery, Niamey National Hospital, Faculty of Health Sciences, Abdou Moumouni University of \\ Niamey, Niamey, Niger \\ ${ }^{2}$ Department of General and Digestive Surgery, Zinder National Hospital, Faculty of Health Sciences, University of Zinder, Zinder, Niger \\ ${ }^{3}$ Department of Anaesthesia and Critical Care, Niamey National Hospital, Faculty of Health Sciences, Abdou Moumouni University of \\ Niamey, Niamey, Niger
}

Email address:

harissou1976@yahoo.fr (H. Adamou)

${ }^{*}$ Corresponding author

\section{To cite this article:}

Rachid Sani, Harissou Adamou, Lassey Didier James, Ibrahim Amadou Magagi, Younssa Hama, Adama Saidou, Kadi Idé, Illa Hamidine, Hadjara Dady, Maman Sani Chaibou. Outcomes of Management of Anal and Perianal Suppuration at Niamey National Hospital, Niger. Journal of Surgery. Vol. 6, No. 4, 2018, pp. 101-106. doi: 10.11648/j.js.20180604.15

Received: July 9, 2018; Accepted: July 19, 2018; Published: August 14, 2018

\begin{abstract}
Bakground: Anal and perianal sepsis is common anorectal disorders found in surgical practice. This study aims to report epidemiological aspects and outcomes of management of anal and perianal suppuration. Methods: This was a retrospective study from January 2011 to June 2016 at Niamey National Hospital. Patients operated on for anal and perianal suppuration of non-specific anorectal origin were included. Results: During the study period, we collected 141 cases of anal and perianal suppurations. The average age of our patients was $42 \pm 8.8$ years. The sex ratio was 3.27 in favor of men. The origin of the patients was urban in $73.8 \%$ of the cases. The history of diabetes mellitus was found in $14.2 \%(\mathrm{n}=20)$. Anal fistulas and anal abscesses $(n=115)$ were simple in $46 \%(n=53)$ and complex in $54 \%(n=62)$. A fistulectomy with the placement of an elastic seton was performed for $41.13 \%$ of cases $(\mathrm{n}=58)$ and fistulotomy in $29.78 \%$. The evolution of 6 months was marked by a recurrence in $10.63 \%(n=15)$, the anal incontinence of gas at $9.21 \%(n=13)$. Deaths $(n=4)$ were recorded in patients with Fournier's gangrene. Uncomplicated therapeutic success was $80.13 \%(n=113)$. Conclusion: The surgical treatment of anal fistula (the main cause of anal and perianal suppuration) aims to eradicate the suppuration and to preserve the anal continence. The fistulotomy done in the context of the management of a simple fistula gives a better outcome. Incontinence-related complications and relapses must impose thoroughness and patience in the surgical treatment of complex fistulas.
\end{abstract}

Keywords: Anal Fistula, Perianal, Abscesses, Cryptoglandular, Fistulectomy, Fistulotomy

\section{Introduction}

Anal and perianal suppuration (APS) continues to be a problem for patients and surgeons despite scientific advances in understanding their pathogenesis [1-4]. APS are very old conditions described well before $2200 \mathrm{BC}[5,6]$. Hippocrates had described (430-460 BC) the use of seton in the treatment of anal fistula [2, 5-7]. They affect more often the man than the woman between the $3 \mathrm{rd}$ and 6 th decade [1-9]. The causes are various, but infection cases are classified as cryptoglandular origin by Hermann and Desfosses gland infection in 71 to $80 \%$ [8-10]. Other less common causes of APS are associated with inflammatory diseases such as Crohn's disease, infected anal fissures, pilonidal sinus, specific infections (such as tuberculosis, actinomycosis), urogenital infections, trauma and in some cases of tumors [1, 
$7,9]$. In the diagnostic and therapeutic approach, abscess and fistula are often two stages (acute and chronic) of the same disease [4, 5-7]. Surgical treatment of anal fistula aims to eradicating suppuration trajectory and to preserve the anal continence [5]. Diagnosed abscess should be treated urgently to prevent progression to Fournier's gangrene, especially in debilitated patients [5, 10]. Although the literature is numerous wide world of APS, few studies exist in Niger. In this work, we report our experience on the epidemiological aspects and outcomes of management of anal and perianal suppuration.

\section{Patients and Methods}

This was a retrospective study during the period between January 2011 and June 2016 (5 years and 6 months) at Niamey National Hospital, Niger. Inclusion criteria were patients underwent surgery for anal and perianal suppuration of anorectal origin: anal abscesses, fistulas complicated or not with Fournier's gangrene (Figure 1) and anal fissure. Exclusion criteria for this study were patients with nonexploitable records, non-cryptoglandular fistula (i.e specific perianal infections, malignant neoplasms, traumatic origin, fistula due to inflammatory disease), cases of Fournier gangrene of urogenital origin, and all perianal suppuration whose origin did not anorectal (pilonidal sinus, Verneuil's disease, cutaneous furuncle, herpes, suppurative hydrosadenitis). The following variables were collected: age, sex, medical history, time to admission, clinical forms, location of fistula orifices, laboratory tests, surgical treatment and evolution. Anal fistulas were classified into 2 groups according to the recommendation of the experts: on the one hand the low fistula (simple fistula) not implying the external sphincter significantly, and, on the other hand, the complex or high forms of fistula with risk of reaching sphincter during surgical treatment $[5,11,12]$. A sitz bath and antibiotherapy combining cephalosporins and metronidazole modified according to the antibiogram were indicated to all patients perioperatively. A follow-up to 6 months was done to evaluate the surgical outcomes. Excel and Epi-info7TM-CDC software were used to record and analyze the data collected in a survey form.
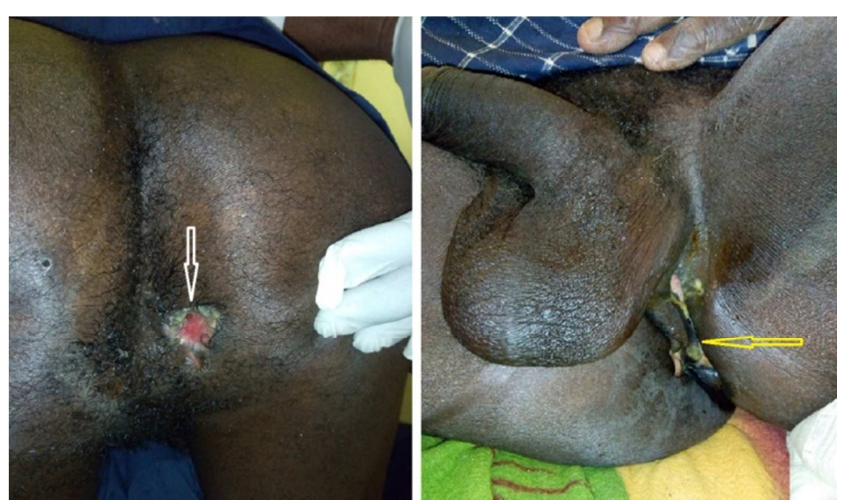

Figure 1. A: External orifice of the anal fistula (white arrow). -B: Fistula anal complicated with Fournier gangrene after debridement (yellow arrow).

\section{Results}

During the period of study, one hundred forty-one patients with anal and perianal suppuration were collected, out of 16040 general surgery admissions (i.e. $0.87 \%$ of cases).

The average age was $42 \pm 8.8$ years with extremes ranging from 18 years to 86 years. The age group range to $35-54$ was the most representative at $49.65 \%$. Patients were predominantly male, $76.6 \%(n=108)$, i.e. sex ratio of 3.27 . Table 1 give the details of the age and sex of the patients.

Table 1. Distribution of patients by age group and sex.

\begin{tabular}{llll}
\hline \multirow{2}{*}{ Age (years) } & Sex & Total (\%) \\
\cline { 2 - 3 } & Female & Male & $1(0.7)$ \\
\hline $15-19$ & 0 & 1 & $43(30.5)$ \\
$20-34$ & 13 & 30 & $70(49.6)$ \\
$35-54$ & 17 & 53 & $21(14.9)$ \\
$55-69$ & 2 & 19 & $6(4.3)$ \\
Over 70 years & 1 & 5 & $141(100)$ \\
Total & $33(23.4)$ & $108(76.6)$ & \\
\hline
\end{tabular}

Our patients come from urban areas in $73.8 \%$ of cases $(n=$ $104)$ and rural areas in $26.2 \%(\mathrm{n}=37)$. The admission time from the onset of symptomatology was between 3 and 30 days for $56.74 \%(\mathrm{n}=80)$, more than 30 days for $34.75 \%(\mathrm{n}=$ $49)$, and less than 2 days for $8.5 \%(n=12)$. The medical history was found in 37 patients including 20 cases of diabetes mellitus (14.2\%), Table 2 .

The anal fistula was responsible for suppuration in $71 \%$ of cases $(n=100)$, the anal abscess was found in $10.5 \%$ of cases $(\mathrm{n}=15)$ and suppuration was complicated by Fournier's gangrene in $15 \%$ of patients $(n=21)$. The anal fissure was responsible for anal suppuration in $3.5 \%$ of cases $(n=5)$. Of the 21 complicated Fournier gangrene patients, 15 (71.14\%) were diabetic mellitus and four (19.04\%) were infected with HIV.

Table 2. Distribution of patients by medical history.

\begin{tabular}{lll}
\hline Medical history & Frequency & Percentage (\%) \\
\hline Diabetes mellitus & 20 & 14.18 \\
High blood pressure & 8 & 5.67 \\
HIV infection & 4 & 2.84 \\
Nephropathy & 3 & 2.12 \\
Peptic ulcer & 3 & 2.12 \\
Other cases $*$ & 3 & 2.12 \\
No history & 104 & 73.75 \\
Total & 141 & 100 \\
\hline
\end{tabular}

*: Rheumatism (1 case), pulmonary tuberculosis ( 1 case), gastroenteritis (1 case).

Among the 100 cases of anal fistula, the external orifice of the purulent flow was unique in $57 \%$, double in $21 \%$ and multiple in $22 \%$ of cases. The anatomical location of the external orifices distributed according to their position at the anus, in $51 \%$ of the external orifice of the fistula was posterior, $22 \%$ lateral right, in $21 \%$ lateral left and $6 \%$ anterior. In this series, in patients with anal fistula and anal abscess $(n=115)$, the primary orifice of the fistula was found during digital rectal examination and/or rectoscopy in 43 patients, i.e. $30.50 \%$. 
After the clinical examination and under general or locoregional anesthesia, anal fistulas or anal abscesses $(\mathrm{n}=$ $115)$ were simple in $46 \%(\mathrm{n}=53)$ and complex in $54 \%$ $(n=62)$. Of the complex fistulas, 59 were transphincteric and 3 were suprasphincteric. Fistulography was done in 16 cases and diagnosed 3 cases of suprasphincteric fistulas (Figure 2).

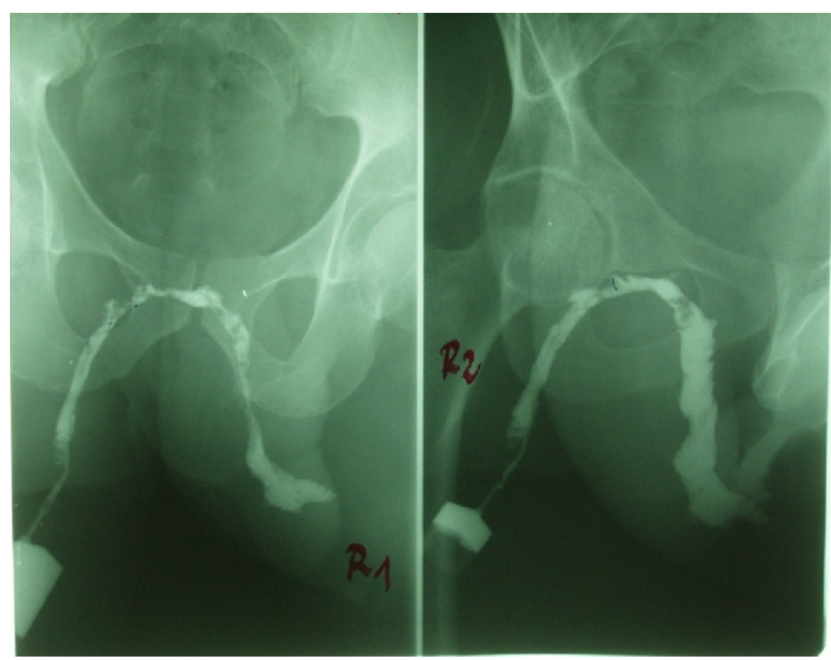

Biological examination, including blood counts, showed leukocytosis greater than 10,000 per microliter in $63 \%$ of cases $(\mathrm{n}=89)$. The pyoculture performed in 22 cases $(15.60 \%)$, found several germs: Echerichia coli $(\mathrm{n}=7)$, Staphylococcus aureus $(n=5)$, Proteus Mirabilis $(n=5)$, Klebsiella pneumonia, Staphylococcus epidermidis, Staphylococcus aureus + Protein and Streptococcus with 1 case each.

As part of the surgical treatment, 41.13\% $(n=58)$ had fistulectomy with the placement of an elastic seton and $29.78 \%(n=42)$ of a fistulotomy. Follow up at 6 months was marked by a recurrence rate of $10.63 \%(n=15)$. The anal gas incontinence was recorded in $9.21 \%(\mathrm{n}=13)$, but this complication only affected patients with complex fistulas. Deaths $(n=4)$ were recorded in the Fournier gangrene group. Treatment and evolution data are found in Table 3. Uncomplicated therapeutic success was recorded in 113 patients, i.e. $80.14 \%$.

The average length of stay was 7 days with extremes of 2 to 72 days. In our sample, $53.90 \%$ of our patients had the duration of hospitalization $\leq 10$ days, all pathologies combined.

Figure 2. Fistulography showing a suprasphincteric trajectory.

Table 3. Distribution of patients by surgical outcomes.

\begin{tabular}{lll}
\hline Causes of suppuration & Surgical procedures & Unfavorable evolution \\
\hline Anal fistula & Fistulectomy $(\mathrm{n}=58)$ & 6 recurrences $(10.34 \%)$ \\
& Fistulotomy $(\mathrm{n}=42)$ & 2 recurrences $(4.76 \%)$ \\
Anal abscess & Flattening $(\mathrm{n}=15)$ & 4 recurrences $(26.66 \%)$ \\
Fournier's Gangrene $(\mathrm{n}=21)$ & Debridement $(\mathrm{n}=21)$ & Septic shock $(\mathrm{n}=5)$ and 4 deaths \\
& Colostomy $(\mathrm{n}=1)$ & 3 recurrences $(60 \%)$ \\
& Cutaneous graft $(7)$ & \\
\hline
\end{tabular}

\section{Discussion}

The anal and perianal suppuration (APS) constitute a group of various affections, with several etiologies $[1,6,11]$. APS mainly arises from anorectal abscesses and classified as cryptoglandular in origin $[2,5,6]$. They are rarely independent of the anorectal area (pilonidal sinus, Verneuil's disease, cutaneous furuncle, etc. [1, 5].

In our study, cryptoglandular origin of APS accounted for $96.5 \%$. According to data in the literature, infection of the Hermann and Desfosses glands is responsible for anal and perianal suppuration in 70 to $95 \%$ of cases $[2,5,6,9,10]$. The infection of these glands (6 to 8 in number) would lead to the formation of an intersphincteric abscess that can evolve either towards regression or towards diffusion in the intersphincteric space or through the external anal sphincter. Thus constituting the anal fistula [2, 6, 9]. Other less common causes of APS include anal fissure, Crohn's disease, trauma, surgery, and specific infections such as actinomycosis and tuberculosis or $[1,2,5]$. In this study, infected anal fissure represents only $3.5 \%$ of our patients.
The glands of Hermann and Desfosses reach the crypt level of Morgani (line of crypts) and are more numerous in men than in women [1-7]. In this study, men were in the majority with a sex ratio of 3.27. Several studies have reported that men are more risk to develop anal abscesses or fistula than women $[2,6,9,11,12]$. The sex ratio varies from 2 to more than 3 [13-19]. The average age of our patients was 42 years old. This is consistent with the results of Bagny et al [14] in Togo who found an average age of 41.8 years. APS are a common condition in surgical practice. The incidence of anal fistulas is approximately 1 to 28 in 10,000 , occurring in $80 \%$ of patients between 30 and 50 years of age $[1,2,10$, 13, 18, 19].

Anorectal abscesses complicated to Fournier's gangrene accounted for $15 \%$ of our series. This could be explained by the delay of consultation related to the modesty and the shame of the patients facing the affections of the anal/perineal parts, but also to the belief in the traditional treatment as the first resort which leads to an admission in a health facility that in case of complications. The relationship is evident between anorectal abscesses and fistulas. In patients presenting for anorectal abscesses and fistulas, 
perianal abscess occurred in $40-42.7 \%$, ischiorectal in 20 $22.7 \%$, intersphincteric in $21.4 \%$ and supralevator in 7.0 $7.33 \%$ of cases [6]. Most patients with fistula will have had a recognizable abscess before presentation. Roughly one third of patients with anorectal abscess will have concomitant fistula at the time of presentation [2]. In general, the clinical examination combining inspection, palpation and digital rectal examination makes it possible to diagnose low (simple) fistula. However in some cases the diagnosis of complex suprasphincteric fistulas can be difficult to require further complementary examinations $[1,6]$. Currently, in developed countries, when clinical examination or endorectal ultrasound are not conclusive, computed tomography scan or magnetic resonance imaging (MRI) remains the reference and effective method, the most sensitive and the most specific to explore perianal abscesses or infected fistulous tracts [1, 2, 20-23]. For Siproudhis [20], nowadays, the exploration of suppuration under general anesthesia is not a reference strategy for diagnosis. However, in our context, this method of examination under general or locoregional anesthesia is still relevant and sometimes the complexity of the fistula is discovered intraoperatively.

Anorectal abscesses and anal fistula are common disorders experienced by emergency department practitioners, surgeons and infectious diseases [1, 2, 6, 9]. In this study, anal fistula, abscess and fistula complicated by Fournier's gangrene accounted for $71 \%, 10.5 \%$ and $15 \%$ of our patients, respectively. Standard surgical treatment is governed by the same principles, since it involves 2 progressive stages of the same disease (abscess then fistula) [5, 7]. Their management depends on the clinical picture that can be done in an emergency or in scheduled surgery. In the abscess or Fournier's gangrene stage, incision drainage/or debridement should be undertaken at emergency in order to avoid complications due to septic shock or even death of the patient [5, 7, 18 ]. However, for Zeitoun et al. [4], in case of emergency suppuration performed by "simple" incision, there is a substantial rate of recurrence ranging from 12 to $41 \%$. This makes it possible to recommend the complete treatment of APS (abscess and fistula) at once. Indeed, the incision of the abscess without fistula cure leaves a scar and can lead a simple fistula to become complex [4]. However, in our study, we made a simple incision of all cases of the abscess without considering the cure of the anal fistula.

The goals of surgical treatment for patients with anal fistula are to eradicate fistula track, to drain associated sepsis, to prevent recurrence and to preserve anal sphincter integrity. This implies the preservation of sphincter function $[1,2,5,6$, 20-27]. For the sake of rationality and care practice, classification can be limited to high fistulas (complex fistulas) and low fistulas (simple fistulas) [20]. Thus the surgical technique will depend on low or high fistula (significantly affecting the sphincters: trans-sphincteric superior or supra-sphincteric) $[1,2,5,11,12,26]$. The recognition of the orifices (external and internal, of the main fistulous tract which are essential elements for its management $[1-5,20,27]$. For Parks et al. [12], 'It's impossible to perform operations without accurate anatomical knowledge, and this is particularly true in the case of fistula in-ano where intemperate surgery can lead to such disastrous results. It is, therefore, most instructive to read the literature of the anatomical concepts which surgeons have held regarding this disease."

In our study, fistulectomy with an elastic seton was performed in $41 \%$ of cases and the recurrence rate was $10.34 \%$. The fistulotomy was done for 42 patients $(29.78 \%)$ of our series with a recurrence rate of $4.76 \%$. When the fistulas are simple or low, i.e. minimal involvement of the muscular sphincter (subcutaneous fistulas, interphincteric fistulas or low transsphincteric fistulas); the treatment of choice in these patients is fistulotomy with a low recurrence rate $(11 \%)[1,2,6,5,17,22]$. Fistulotomy remains the standard surgical treatment for low anal fistulas, but presents a risk of sequential continence disorders for high fistula [20, $24,27]$. Indeed, the success rate of this procedure ranging from 84 to $95 \%$ [18, 24-27]. On the other hand, the option of fistulectomy treatment with the placement of elastic seton (progressive elastic traction) should be considered in patients with complex fistula with significant sphincter involvement $[1,2]$. Fistulotomy cannot be performed at a time because of the high risk of incontinence [1,2]. "If low fistulas can be the subject of a fistulotomy without major risk, the greatest prudence is of rigor for the high, complex fistulas, which must be the subject of the fractionation of the operating times to dry up the suppuration, while trying to preserve continence at best"[5]. It will be proposed to cut the sphincter in a progressive way (flattened in several times or by elastic necking) [5, 8]. Fistulectomy with elastic tightening was the technique most used in our study.

The risk of anal incontinence after surgery for an anal fistula crossing the sphincter varies from 5 to $30 \%$ according to the literature. This risk is directly related to the relationship between the fistula and the degree of involvement of the sphincter [1, 5, 22-27]. In our series, the rate of gas incontinence was $9.21 \%$ of all patients with high fistulas. The functional risk having a major impact on the patient, several alternatives are currently proposed to the surgical treatment $[1-3,5,10-13,27]$. Four techniques are the most evaluated: the anorectal advancement flap, the injection of biological glue, the placement of a plug and the interphincteric ligation of the fistulous tract [3, 5, 20-27]. Some also propose a treatment by gluing for complex fistulas as well as for simple fistulas [5, 27].

\section{Conclusion}

Anal fistula is the main cause of anal and perianal suppuration in this study. Surgical treatment aimed to eradicating suppuration and preserving anal continence still presents a challenge for the surgeon especially in the cases of transphincteric and suprasphincteric fistulas. The fistulotomy done in the context of the management of a simple fistula gives a better result. Fatal complications such as Fournier's gangrene can enamel the evolution of anal suppuration. But 
in general, these occur on fragile ground often diabetic mellitus or immunocompromised. Incontinence-related complications and recurrences must impose thoroughness in the surgical treatment of anal and perianal suppuration.

\section{Conflicts of Interest}

The authors declare that they have no competing interests.

\section{Authors' Contributions}

Each author contributed substantially to manuscript.

SR: Substantial contributions to conception and design, acquisition of data, analysis and interpretation of data; writing the original manuscript, and revising it critically for important intellectual content.

HA: Contributions to conception and design, to bibliographic research, to analysis and interpretation of data, to drafting the article, and revising it critically for important intellectual content.

LJD, IAM, YH, AS, KI, IH, HD, MSC: Contributions to analysis and interpretation of data and drafting the article, revising it critically for intellectual content.

All authors read and approved the final manuscript.

\section{References}

[1] Ommer A, Herold A, Berg E, Furst A, Post S, Ruppert R, et al (2017). German S3 guidelines: anal abscess and fistula (second revised version). Langenbecks Arch Surg; 402 (2):191-201. doi: 10.1007/s00423-017-1563-z.

[2] Sugrue J, Nordenstam J, Abcarian H, Bartholomew A, Schwartz JL, Mellgren A, Tozer PJ (2017).. Pathogenesis and persistence of cryptoglandular anal fistula: a systematic review. Tech Coloproctol. 21 (6):425-432.

[3] de Parades V, Zeitoun JD, Atienza P (2010). La fistule anale cryptoglandulaire. J Chir Visc 147 (4):265-277.

[4] Zeitoun JD, de Parades V (2016). Abcès anal: lors de l'intervention de drainage, faut-il chercher et traiter la fistule ? Colon Rectum; 10 (1):76-79.

[5] Abramowitz L, Allez M, Devulder F, Faucheron JL, Ganansia R, Soudan D, Tarrerias AL (2010). In: Fistules anales. La «Collection SNFCP». Springer, Paris 2010; 103 pages. https://doi.org/10.1007/978-2-8178-0019-6 4.

[6] Wright WF (2016). Infectious Diseases Perspective of Anorectal Abscess and Fistula-in-ano Disease. Am J Med Sci; $351(4): 427-34$.

[7] Fathallah N, Ravaux A, de Parades V, Pommaret E, Crochet E, Ganansia O (2017). Conduite à tenir face à un abcès anopérinéal. Ann. Fr. Med. Urgence; 7:174-182.

[8] Pigot F (2015). Traitement des fistules anales abcédées ou non. J Chir Visc, 152 (2): S22-S28.

[9] Amato A, Bottini C, De Nardi P, Giamundo P, Lauretta A, Realis Luc A et al (2015). Evaluation and management of perianal abscess and anal fistula: a consensus statement developed by the Italian Society of Colorectal Surgery
(SICCR). Tech Coloproctol; 19 (10):595-606.

[10] Neto I. J F C, Wercka J, Rangel DP, Lopes EA., Watté HH, Souza RFL et al (2017). Retrospective analysis of patients submitted to surgical treatment of perianal fistula in Santa Marcelina Hospital, São Paulo. J coloproctol; 37 (3), 193-198.

[11] Arnous J, Denis J, \& Puy-Montbrun T (1980). Les suppurations anales et périanales. À propos de 6500 cas. Concours Med, 12, 1715-29.

[12] Parks AG; Gordon PH, Hard Castle JD (1976). Classification of fistula in ano Br. J Surg; 63:1-12.

[13] Hasbi, S (2017). Traitement chirurgical des fistules anales cryptoglandulaires. Étude rétrospective chez 64 patients. J Afr Hepato Gastroenterol (2017) 11 (4): 152-154.

[14] Bagny A, Lawson-Ananissoh, LM., Bouglouga O, El Hadji YR., Kaaga LY, Redah, D, Djibril, MA (2017). La pathologie anorectale au chu campus de Lomé (Togo). Eur Sci JournalESJ; 13 (3): 423-248.

[15] Kouadio GK, Kouadio LN, Turquln HT (2015). Prise en charge de la fistule anale au CHU de Treichville à Abidjan. A propos de 47 observations. Rev. CAMES - Série A, Sciences et Médecine; A-2: 45-47.

[16] Mathusoothanan, P., \& Venugopal, ER. A (2018). Clinical Study on Perianal Abscess. Stanley Medical Journal; 4 (4), 68.

[17] Sissoko F, Ongoiba N, Coulibaly Y, Coulibaly B, Doumbia D, Dembélé M, et al (2003): Fistules anales à l'hôpital du point $\mathrm{G}$ à propos de 164 cas. Mali Méd; 18 (1\&2): 25-28.

[18] Bakari AA, Ali N, Gadam IA, Gali BM, Tahir C, Yawe K, et al (2013). Fistula-in-Ano Complicated by Fournier's Gangrene Our Experience in North-Eastern Region of Nigeria. Niger J Surg. 2013; 19 (2):56-60.

[19] Oueidat D, Assi TB, Youssef L, Rizkallah A., Zerbe R, Cappello F et al (2015). A 30 year experience in the management of anal fistula. Euromediterranean Biomedical Journal, 12 (39) 184-188.

[20] Siproudhis L (2015). Fistules anales: deux doigts de prudence et un doigt d'expertise! Hépato-Gastro \& Oncologie Digestive; 22 (9):837-9.

[21] Khati NJ, Sondel Lewis N, Frazier AA, Obias V, Zeman RK, Hill MC (2013). CT of acute perianal abscesses and infected fistulae: a pictorial essay. Emerg Radiol.; 2 (3):329-35.

[22] Joy HA, Williams JG (2002). The outcome of surgery for complex anal fistula. Colorectal Dis.; 4 (4):254-261.

[23] Garg P (2018). Understanding and Treating Supralevator Fistula-in-Ano: MRI Analysis of 51 Cases and a Review of Literature. Dis Colon Rectum; 61 (5):612-621. doi: 10.1097/DCR.0000000000001051.

[24] Rickard Matthew J F X (2005). Anal abscesses and fistulas. ANZ J. Surg.; 75: 64-72.

[25] Davies M, Harris D, Lohana P, Chandra Sekaran TV, Morgan AR, Beynon J, Carr ND (2008). The surgical management of fistula-in-ano in a specialist colorectal unit. Int J Colorectal Dis. 2008 S; 23 (9):833-8. doi: 10.1007/s00384-008-0444-X. 
[26] Cadeddu F. Salis F Lisi G. Ciangola I. Milito G (2015). Complex anal fistula remains a challenge for colorectal surgeon. Int J Colorectal Dis.; 30 (5):595-603. Doi: https://doi.org/10.1007/s00384-014-2104-7.
[27] de Parades V, Pommaret E, Fathallah N, Zeitoun JD, Bouchard D, Brochard C et al (2017). Fistules anales en 2017: les techniques d'épargne sphinctérienne ont-elles fait long feu? Hépato-Gastro \& Oncologie Digestive; 24 (5), 427-430. 